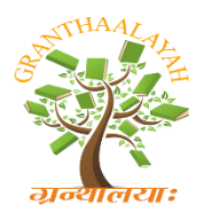

\author{
INTERNATIONAL JOURNAL OF RE
GRANTHAALAYAH \\ A knowledge Repository
}

Science

\title{
SOCIAL NETWORKS AND THEIR INFLUENCE ON THE SEXUALITY OF THE TEENS EDUCATIONAL UNIT
}

\author{
MSc. Rocio Fonseca Tumbaco ${ }^{1}$, DR. Jorge Elias Dáher Nader ${ }^{2}$, MSc. Cecilia Herrera \\ Martinez $^{3}$, MSc. Yesica Pazmiño Mera ${ }^{4}$, Odont Evelyn Navarrete Fonseca ${ }^{5}$ \\ 1,2, 3, 4, 5 Teachers of The Career of Obstetrics of The Faculty of Medical Sciences of The \\ University of Guayaquil-Ecuador
}

\begin{abstract}
Sexual intercourse at an early age is a public health problem, because they are associated with various health consequences such as early pregnancy, school drop-out, pre-term births, etc. The study was carried out on 120 adolescents from the baccalaureate, Eugenio Espejo educational unit of the city of Guayaquil - Ecuador, in the 2018-2019 school year. The descriptive, quantitative and analytical methodology of a transversal cohort was applied, considering the use of the survey. As a result of the investigation, the need to develop a sexual education program and the appropriate use of social networks was evidenced, which would be totally innovative because in the present moment no educational institution has carried out a study of this nature, to avoid relationships Early sexuality, minimizing high school dropout and the proper use of social networks in adolescents, therefore it is concluded that adolescents are exposed to the danger of social networks because they use it with high frequency, usually several times a day, without any control of their parents or legal representatives, which affects their cognitive and emotional development, a sexual education program will be implemented for the appropriate use of social networks.
\end{abstract}

Keywords: Social Networks; Sexual Relationship; Adolescence.

Cite This Article: Rocio Fonseca Tumbaco, DR. Jorge Elias Dáher Nader, Cecilia Herrera Martinez, Yesica Pazmiño Mera, and Odont Evelyn Navarrete Fonseca. (2020). "SOCIAL NETWORKS AND THEIR INFLUENCE ON THE SEXUALITY OF THE TEENS EDUCATIONAL UNIT." International Journal of Research - Granthaalayah, 8(2), 47-56. https://doi.org/10.29121/granthaalayah.v8.i2.2020.183.

\section{Introduction}

Early sexual intercourse is a public health problem, because they are associated with various negative consequences of a sanitary type, because they imply a higher risk of teenage pregnancy and the acquisition of sexually transmitted infections, which in turn increase the costs of health care. this priority group and generate dropout and underdevelopment. (Paulin, and others, 2013). 
Sexual activity in Latin America takes place every year at an earlier age according to UNICEF, in this region young people begin sexual relations in an average of approximately 13.5 to 15 years, including almost $50 \%$ of men and $43 \%$ of women are sexually active before age 17 , for example, $14 \%$ of those under 15 in Colombia have already had intercourse, as well as $60 \%$ of those under 17, in Brazil, more than $20 \%$ of those 15 -year-olds had already had at least one intercourse. (Mendoza, Claros, \& Peñaranda, 2016).

In Ecuador, the CERCA Project of European origin, conducted in 2012 the survey to determine the beginning of sexual relations of 3,300 adolescents who were part of the population sample, determined that the average age of the first intercourse was 14 years for men and 15 for women, a situation that was earlier than the results of the Endemain demographic survey conducted in 2004, which was 17 years on average. (Pan American Health Organization, 2013).

Although it is true, the indicators about the beginning of sexual relations in adolescence, show that not only in Ecuador, but in most Latin American countries, they begin at an earlier age, which is why we want to know If the technological devices have had an influence on this phenomenon, because in the country their evolution was greater in the last decade.

In the seventh national youth survey prepared by the Ministry of Social Development (Ministry of Social Development, 2012) almost half of the population between 15 and 21 years old - that is $48 \%$ of young people - says they connect to the Internet all On days, the youngest population between 15 and 19 years of age is the one with the highest internet access, since $51 \%$ of the population connects daily.

They give great emphasis to the risks that can be found in the use of the internet by children and adolescents, of which the exposure of inappropriate material such as violence or sexuality, the transmission of personal data that can be stolen by unknown people, planning appointments through chat with unknown people in unwanted places, the reception of messaging with aggressive or unpleasant messages for the user and the various addiction problems to which internet users are exposed with serious psychological consequences. Social networks are used primarily for online communication, public sales, sexual services and games.

In this regard, some research has been cited on the influence of information and communication technology in the beginning of sexual relations, such as that carried out by the Spaniards (Fajardo, Gordillo, \& Regalado, 2013), who in their study on sexting and new uses of technology in adolescent sexuality obtained as findings that "adolescents know about friends who use cell phones and the Internet, specifically social networks, for the practice of sending or receiving messages, photos and provocative and erotic videos",

They even know what the term sexting means, although "they did not fully accept that they they also used it directly, but indirectly through their fellow students, relatives or neighbors of the same age neighborhood." A teenager who practices sexting runs several risks that can make him sick, isolate him and even put his safety at risk and as consequences we have: bullying or bullying. extortion and humiliation. 
When conducting the literature review, the thesis called the influence of the internet on adolescent sexuality was taken, defined in Santiago, Chile, being its author (Acevedo, 2014), who evidenced as the main finding that "students have the Internet as their main ally to learn about sexuality issues, some of them are not precisely educational and usually share them with their peers of the same age ", although a considerable percentage said that" there is also abundant information on responsible sexuality on the Internet, which has nurtured them at some point about the issues inherent in the topic of sex, sexuality and reproductive health ", however, indicate that" it is true that some partners take bad examples and therefore agree to sustain relationships sexual using social networks".

A postgraduate thesis was also carried out at the Rafael Landívar University of Guatemala, whose objective was to determine the factors that influence early sexual relations, considering as a space delimitation the Institute of Basic Education of Chinautla, whose author (Morales, 2014) identified as more relevant findings that influenced early sexual relations, "the media, the Internet and social networks, peer group and friends pressure, misinformation and poor knowledge of sexuality and reproductive health."

Continued to the investigations that keep a close relationship on the subject in treatment on sexual education, we can highlight the study prepared by (Rayo, 2014) entitled "Influence of the use of social networks in family relationships of young people of 18 and 24 years that present addiction to them ", with the main objective of establishing how the use of social networks influences the family relationships of young people who are addicted to them and who attend the Rafael Landívar University. Among the results we can verify that the incidence of social networks with pornographic content in adolescents is due to the lack of communication between family members, and therefore has an impact on university academic performance.

A research recently addressed by the author (Mejía, 2015) from the University of Guayaquil, allowed us to visualize more accurately the impact of this on the adolescent population, since this research called "analysis of the influence of social networks in training of the young people of the schools of the Yaguachi canton", compiles all the factors that condition this problem, so its purpose was to establish the influence that social networks have on the formation of young people through the analysis, to demonstrate in what As these cyber spaces affect the students of the two schools in the city under study. The results reflected that students ignore the influence of web portals, which is why their consumption becomes addictive, in addition to verifying that a significant amount visualizes some sexual content, since they are mostly not supervised by adults, at At the same time it was identified that the most used social networks are Facebook and Whats App.

Another study carried out in Costa Rica by (Giraldo, 2013) established the objective "to analyze the theoretical positions between youth and sexuality, approached from the point of view of social networks", whose results discussed the implications between technology and sexuality, as well as the impact on the relationships of the adolescent population, although it was stated that "social networks can increase risk practices among high school students", however, it was concluded that they "can also give way to new cybernetic identities, where the school must become the entity that promotes respect for sexual identity and the good use of modern technological devices". 
The object of study of this research refers to early sexual relations that have an impact on the biopsychosocial health of adolescents, which represents a problem associated with early pregnancy, health complications in this priority group that has a direct relationship with various Poverty indicators and affects the welfare of students, while the field of action is referred to the influence of social networks.

The problem was raised through the following question: Designing a sexual education program and the appropriate use of social networks in adolescents of the Eugenio Espejo Educational Unit of the city of Guayaquil - Ecuador, in the 2017 - 2018 school year?

The general objective of the research is to design a Sexual Education Program and the appropriate use of social networks in adolescents of the Eugenio Espejo Educational Unit of the city of Guayaquil - Ecuador in the period April 2017 - January 2018, whose specific objectives are following:

- Identify the devices used by adolescents to obtain the information.

- Set the frequency of device use.

- Determine the influence of social networks on sexual relations at an early age and the approach of preventive and educational measures,

Not only can it prevent early pregnancy, but it will also strengthen the biopsychosocial health of adolescents, to minimize school dropout, save resources to the State for health care of this priority group, in addition to contributing to the good living of the population under 19 years of age. (National Constituent Assembly, 2008), (National Secretariat for Development Planning, 2017). This statement justifies the present investigation, because it refers to the importance of the development of the study, which aims to establish appropriate preventive and educational measures so that adolescents studying in high school can avoid the maintenance of early sexual intercourse and can feel greater concern for their studies, with a view to achieving lasting development in the immediate future.

For this reason, through the application of the Sexual Education Program, the appropriate use of social networks by adolescents of the Eugenio Espejo Educational Unit of the city of Guayaquil Ecuador will be promoted, for the benefit of young people who must recognize that Sexuality is a very important area of life and they act responsibly to achieve greater development in this field, while also benefiting parents, legal representatives and the educational community in general.

This research is in accordance with the constitutional principles established in Art. 32 and 44 of the Constitution of the Republic (National Constituent Assembly, 2008) and in the first objective of the National Plan for Good Living a Lifetime (National Secretariat for the Development Planning, 2017), in addition to being sponsored by the University of Guayaquil. That is determined to increase the number of teachers with a PHD degree in this institution of higher education.

\section{Methodology}

The research was observational, descriptive and analytical, and cross-sectional, considering the documentary inquiry of books, encyclopedias and websites on the variables under analysis, in addition to the collection of data using the survey technique applied to the adolescents who are 
educated in the baccalaureate of the Eugenio Espejo Educational Unit of the city of Guayaquil Ecuador.

In the study, adolescents who have had sexual intercourse and who are studying in the baccalaureate of the Educational Unit were considered as the main inclusion criterion, while those who did not have sexual intercourse were excluded, measuring the demographic indicators of this age group, the possession and use of social networks, to diagnose if there is a relationship between information technology and early sexual relations that may have an impact on the physicalbiopsychosocial health of adolescents, to subsequently raise the mechanisms adequate to minimize the risk of minors having sexual intercourse, to promote the fulfillment of the objectives and to respond to the hypothesis.

The investigative instrument to be applied, comes from the survey technique, the population considered in this study are 120 adolescents considering the inclusion and exclusion criteria of the Eugenio Espejo Educational Unit of the city of Guayaquil - Ecuador in the period April 2017 June 2018

\section{Results}

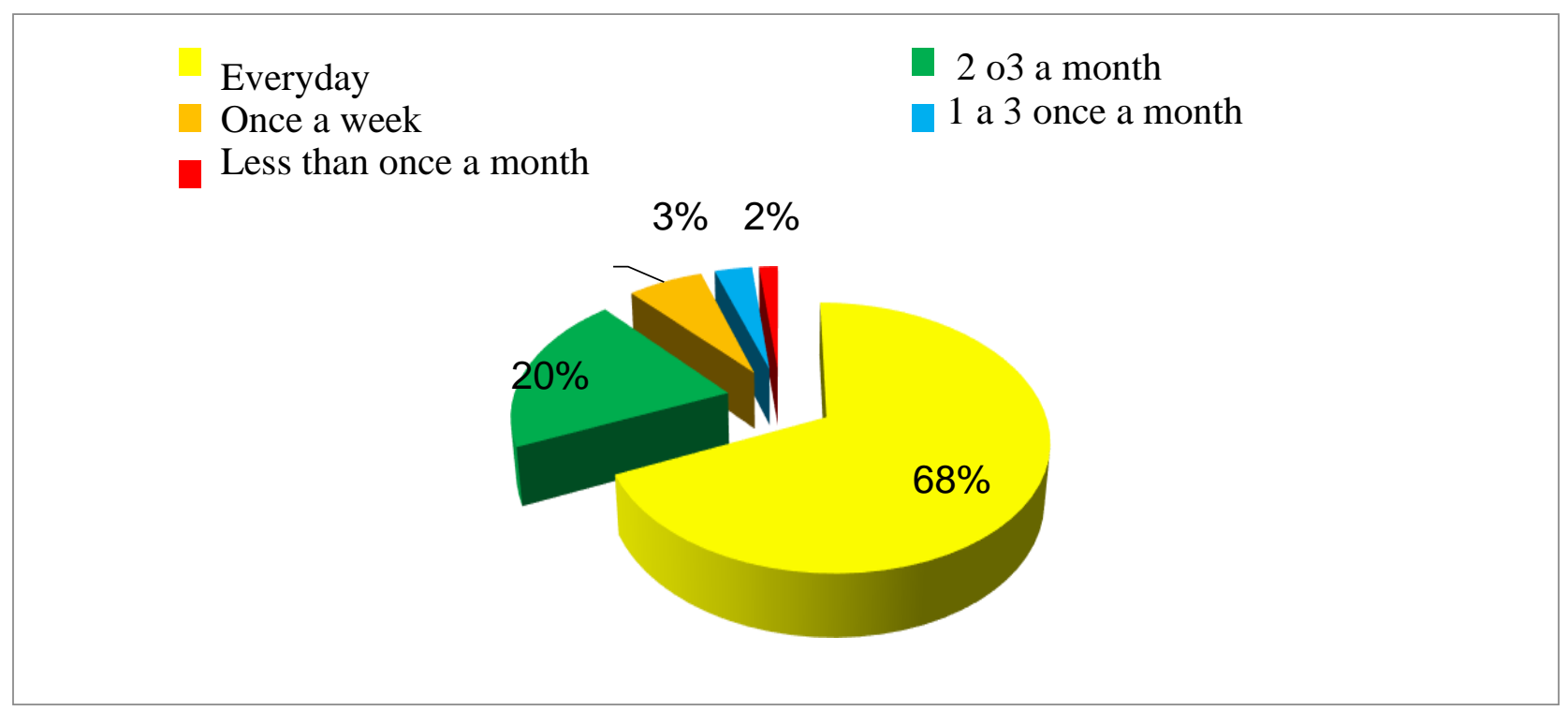

Figure 1: Frequency of use of social networks. Survey applied to high school students of the Eugenio Espejo Educational Unit of Guayaquil, 2018.

Regarding the frequency with which students use social networks, it is obtained that $68 \%$ indicate that they use social networks every day, $20 \%$ indicate that they review them two to three times a week, $7 \%$ He maintains that he uses them once a week, $3 \%$ use them between one to three times a month, while $2 \%$ indicate that they review social networks less than once a month. The information obtained evidences that adolescents use social networks very frequently, since there are currently several applications that allow users to interact with friends and acquaintances that they cannot see personally, however, their use can present a series of disadvantages or dangers, so you should consider its limited use and avoid becoming an addiction. 
To chat with friends

For distraction

To communicate about study topics To

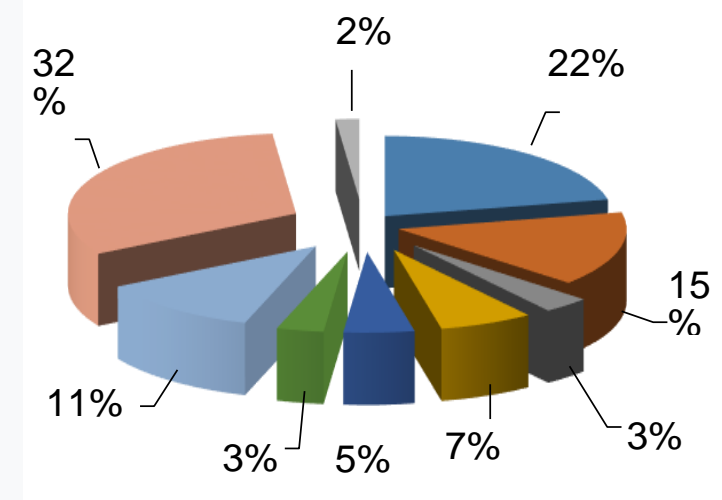

find information about a topic

To annoy

To contact someone in particular

For them to see and be important

To be part of a group

be popular

Figure 2: Main social networks used by teenagers. Survey applied to high school students of the Eugenio Espejo Educational Unit of Guayaquil, 2018.

- To communicate about study topics to find information about a topic to annoy

- To contact someone in particular to be seen

Teenagers were asked what motivates them to use social networks, obtaining that $32 \%$ use it to be part of a group and be popular, $22 \%$ to chat with their friends, $15 \%$ for distraction, $11 \%$ for that they see it and be important, $7 \%$ use them to look for information on a specific topic, $5 \%$ to annoy, $3 \%$ to have contact with someone special. The results obtained allow us to know that students use social networks for various activities, being the most relevant option that indicates chatting with friends and bothering with friends, reflecting that they do not have a specific use for an act of relevance or interest, However, it can affect the individual's behavior when he exaggerates his use and loses control of his publications, comments and content that makes them vulnerable and exposes them to risk situations.

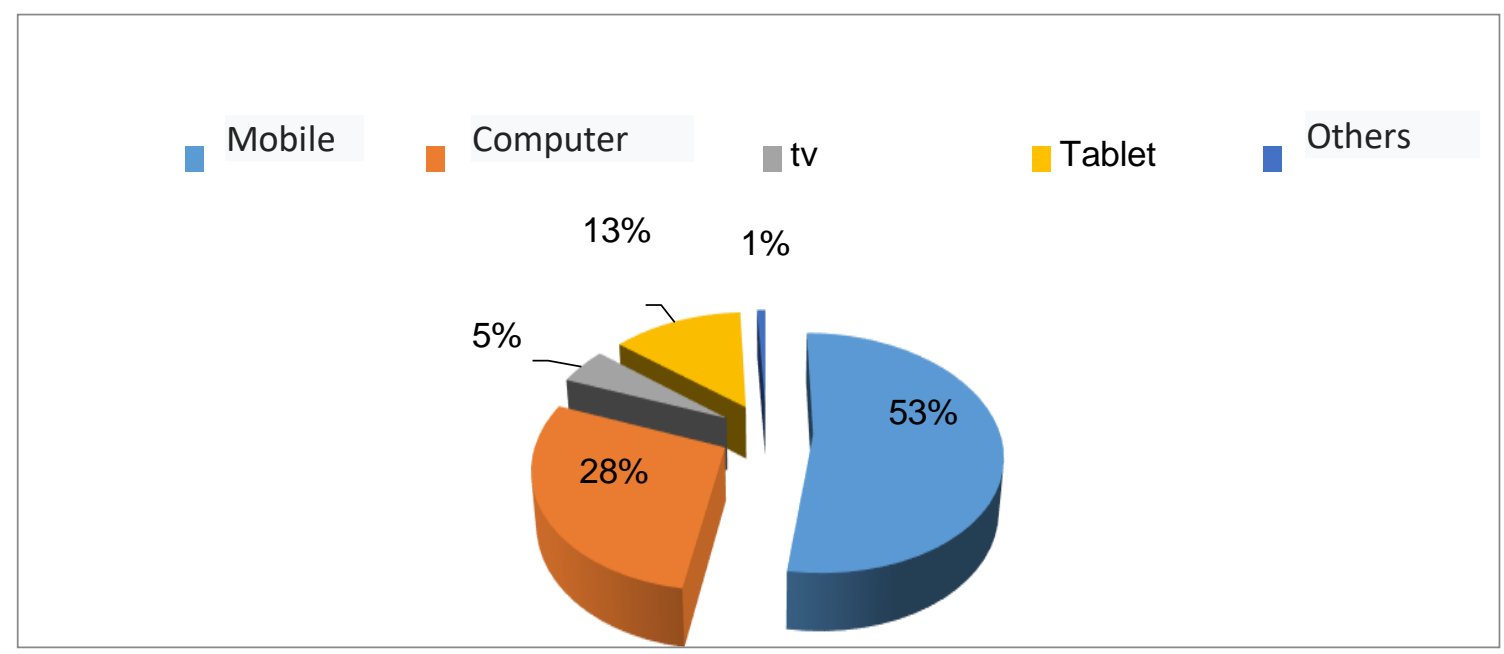

Figure 3: Device used to navigate in social networks. Survey applied to high school students of the Eugenio Espejo Educational Unit of Guayaquil, 2018. 
The majority of teenagers (53\%) use the cell phone to navigate in social networks, while the second and third place is occupied by the computer and the Tablet, with 28\% and 13\% respectively, 5\% use the television and $1 \%$ remaining other digital or electronic devices. These findings clearly show that the cell phone is the most widely used device for browsing social networks and is generally presented by the parents themselves to their children.

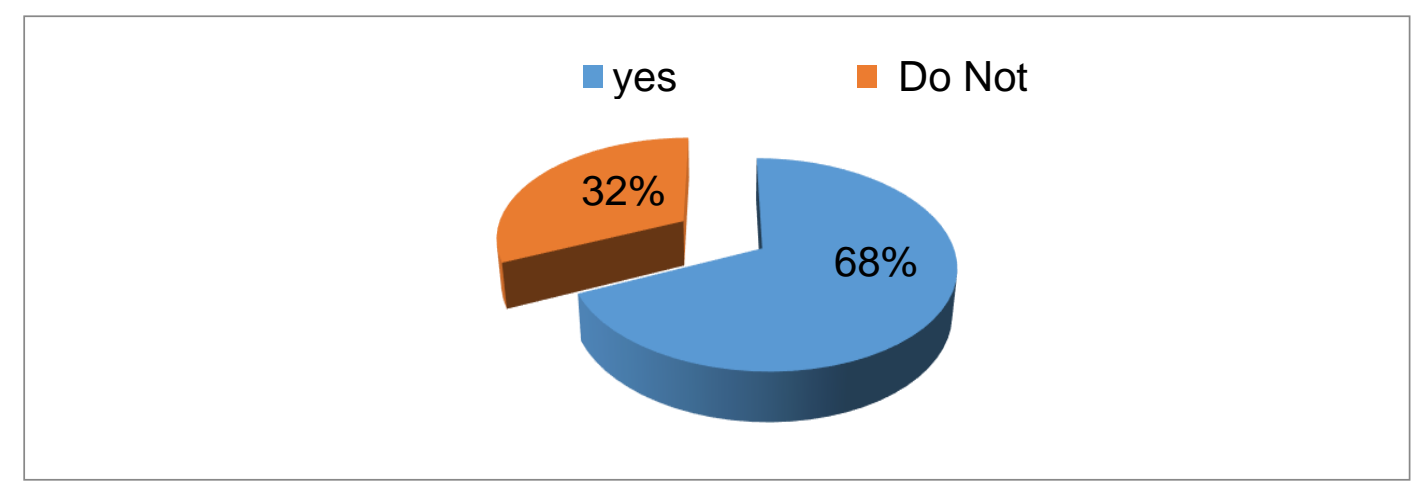

Figure 4: Maintenance of virtual couples. Survey applied to high school students of the Eugenio Espejo Educational Unit of Guayaquil, 2018.

Regarding the experience with virtual partners through social networks, it is obtained that $68 \%$ have experienced maintaining romantic relationships using social networks, while the $32 \%$ say they have not had this type of relationship. The use of social networks is considered a worldwide phenomenon that allows people to display information of personal content and meet people with whom they may have friendship or love relationships known as virtual partners, which has sown interest among young people in to meet people by this means and the importance of knowing the people in the environment has been left aside, this increases the risks in this population since they can be deceived by older individuals who have the objective of harming or harming other people using this medium that parents cannot detect.

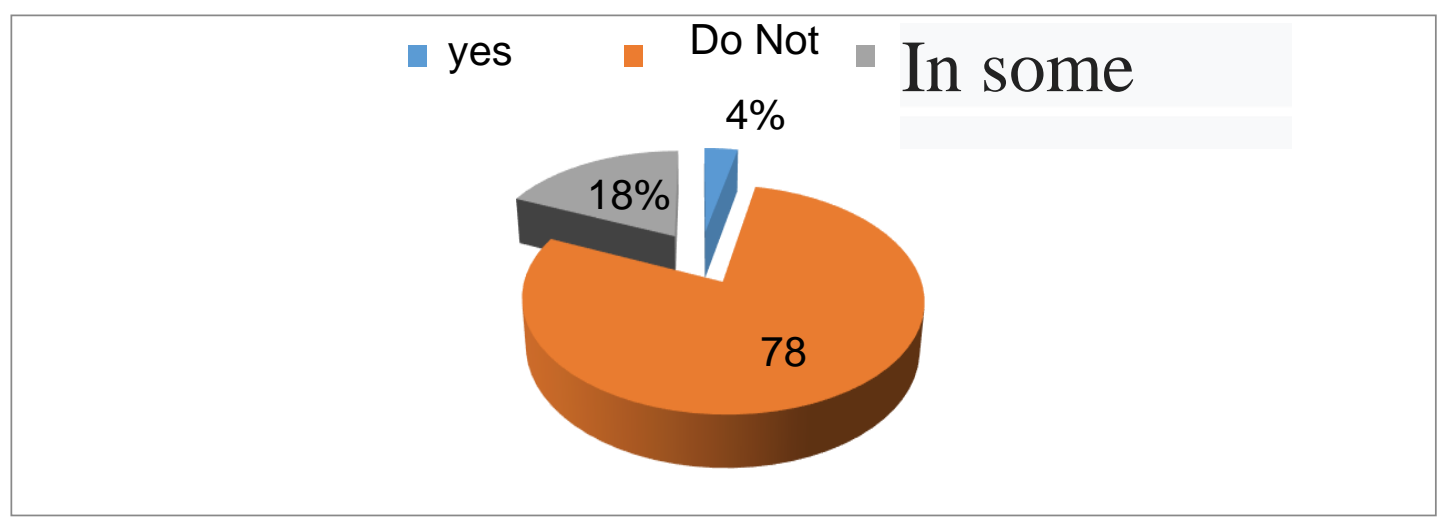

Figure 5: Importance of social networks for sexuality. Survey applied to high school students of the Eugenio Espejo Educational Unit of Guayaquil, 2018.

Regarding the importance of social networks to know about sexuality, it is obtained that $78 \%$ consider that they do not allow access to this information, $18 \%$ maintain that in some cases they can know something about this topic, while 4\% They say they can get information about sexuality. Currently, social networks have become tools that allow communication, information and fun, 
these websites can contain information on different aspects, among which sexuality is highlighted, however it is necessary to review pages with social responsibility, that do not contain grotesque information, since with the increase of users of social networks, the use of unreliable information has increased, therefore everything cannot be believed because they can be myths, simplifications, excesses and confuse adolescents.

\section{Discussion}

The main findings showed that, in effect, social networks constitute an element that is associated with early sexual relations and damage to adolescents' sexuality, because more than two thirds $(68 \%)$ have access to these cyber spaces of Free navigation, very often, specifically every day of the week and several times or hours a day.

The cell phone is the digital device used by more than half of the population of adolescents (52\%), in which you have easy access to social networks and even with privacy, because they can be connected in the bathroom, bedroom or other private places, where they chat with friends and want to be part of a group to gain popularity, almost two-thirds (65\%) of the beneficiary population.

Among the expected results of the research, it is cited first that social networks are affecting the biopsychosocial well-being of adolescents, according to $78 \%$ of the students on campus, because of the promotion, in some cases subliminal, for support of sexual intercourse, whose influence can increase the likelihood of students maintaining sexual intercourse at an early age, so that these results form part of the solid basis for the implementation of a sexual education program, in addition to the appropriate use of networks social, which would be totally new because in the present moments no educational institution has implemented this type of Sex Education program and talk about the appropriate use of social networks.

This means that, based on the findings to be obtained, the authorities of the Eugenio Espejo Educational Unit of the city of Guayaquil - Ecuador and of the education and public health system, will be able to plan and execute the strategy to improve the biopsychosocial health of adolescents, minimizing the probability of having early sexual relations and avoiding school dropout, for the good living of this priority group.

\section{Conclusion}

Adolescents are exposed to the danger of social networks because they use it with high frequency, usually several times a day and a week, without any control of their parents or legal representatives, which not only affects their cognitive development, but also It can also affect the evolution of your skills in the area of sexuality, due to the easy access to pages that can be disorienting in this area. In fact, parents often give cell phones to their children and it is precisely these devices that adolescents use the most, for browsing social networks, including virtual partners and giving importance to sex rather than sexuality.

The findings obtained in the investigation should increase the interest of the health authorities and the Eugenio Espejo Educational Unit of the city of Guayaquil - Ecuador, as well as of the scientific 
community at the national level, so that a sexual education program and of the appropriate use of social networks, necessary to contribute to the improvement of adolescent biopsychosocial health, minimizing the risk of maintaining relationships sexual at an early age and avoiding the negative repercussions that are avoidable, so that the good living of this priority group is maintained.

If the results are positive, the sexual education program and the appropriate use of social networks can be implemented, not only for high school students of the Eugenio Espejo Educational Unit of the city of Guayaquil - Ecuador, but in all educational institutions at the national level, promoting the improvement of the quality of the public service for the welfare of the priority group of adolescents.

\section{References}

[1] Acevedo, B. (2014). Internet influence on adolescent sexuality: knowing how it is perceived by its actors. Santiago de Chile: University of Bío Bío.

[2] National Constituent Assembly. (2008). Constitution of the Republic of Ecuador. Montecristi :: Official Registry 449.

[3] Fajardo, M., Gordillo, M., \& Regalado, A. (2013). Sexting: new uses of technology and sexuality in adolescents. International Journal of Psychology, 1 (1), 18. Retrieved from http://dehesa.unex.es/bitstream/handle/10662/958/0214-9877_2013_1_1_521.pdf

[4] Giraldo, C. (30 of 01 of 2013). Cyber body: youth and sexuality in postmodernity. Investigative News in Education Magazine, 13 (1), 21. Obtained from w.redalyc.org/pdf/447/44725654006.pdf

[5] Ecuadorian Institute of Statistics and Censuses. (2015). Statistical Compendium. Quito, Ecuador: INEC.

[6] Mejía, V. (2015). Analysis of the influence of social networks in the training of young people in the schools of the Yaguachi canton. Guayaquil, Ecuador: University of Guayaquil. School of Social Communication.

[7] Mendoza, L., Claros, D., \& Peñaranda, C. (06 of 2016). Early sexual activity and teenage pregnancy: state of the art. Chilean Journal of Obstetrics and Gynecology, 81 (3), 15. Obtained from https://scielo.conicyt.cl/scielo.php?script=sci_arttext\&pid=S0717- 7526201600030

[8] Ministry of Public Health. (27 of 11 of 2017). Ministry of Health, UNICEF and PAHO promote breastfeeding. Recovered on 03/21/2018, the Ministry of Health, UNICEF and PAHO promote breastfeeding: http://www.salud.gob.ec/ministerio-de-salud-unicef- and-ops-promotebreastfeeding -maternal /

[9] Morales, E. (2014). Factors that influence the early practice of genital sex relations in adolescents of the Chinautla Institute of Basic Education. Guatemala: Rafael Landívar University.

[10] Pan American Health Organization. (04 of 04 of 2013). Sexual intercourse is increasingly early in Ecuador. Retrieved on 03 04, 2018, from Sexual relations are increasingly early in Ecuador: http://www.paho.org/ecu/index.php?option=com_content\&view=article\&id=895:april-4- 2013 \& Itemid $=972$

[11] Paulin, Y., Mendoza, L., Esquivel, C., Sánchez, R., Daraviña, A., \& Acuña, M. (2013). Factors associated with the beginning of sexual activity in adolescents in Tuluá, Colombia. Chilean Journal of Obstetrics and Gynecology, 78 (3), 15. Obtained from https://scielo.conicyt.cl/scielo.php?script=sci_arttext\&pid=S0717-75262013000300007

[12] CESOLAA sex education program. (2014). Sexuality education goals. Chile: http://educacionsexual.uchile.cl/index.php/hablando-de-sexo/la-educacion- sexual / objectives-deeducacion-de-la-sexualidad. 
[13] Rayo, A. (2014). Influence of the use of social networks in family relationships of young people aged 18 and 24 who are addicted to them. Guatemala: Rafael Landivar University. Faculty of Humanities.

[14] National Secretariat for Development Planning. (2013). National Plan of Good Living to Quito, Ecuador: SENPLADES. http://www.buenvivir.gob.ec/.

[15] National Secretariat for Development Planning. (2017). National Plan for Good Living A Lifetime. Quito, Ecuador: SENPLADES.

*Corresponding author.

E-mail address: rocio.fonsecat@ ug.edu.ec/ jorge.dahern@ug.edu.ed

evelynnavarrete@ hotmail.com / yesica.pazminom@ug.edu.ec/cecilia.herreram@ug.edu.ec 